\title{
Resisting Gender: Twenty-Five Years of Feminist Psychology
}

\author{
By Rhoda K. Unger. Sage Publications, London, England, 1998, 239 pp., \$49.95.
}

\author{
Sari M. van Anders
}

Published online: 5 February 2008

(C) Springer Science+Business Media, LLC 2008

This volume is a detailed participant-observer account of feminist psychology over the last quarter of the last century. Unger is well positioned in this body of research, having edited and authored numerous textbooks and research publications on women, gender, and psychology, as well as having been president of the Society for the Psychology of Women (APA Division 35). Unger presents an authoritative account of feminist psychology and its major practitioners, as well as her own contributions, including six reprints of earlier addresses or papers. The volume includes insights about the place of feminist psychology within psychology, methodologies and findings, and future directions.

Because political activism preceded research on women in psychology, some of the early utility of feminist psychology was in empirically demonstrating discrimination and prejudice. The zeitgeist also focused on women's "lesser" achievement, so much of the early research focused on this. Though much of her and her colleagues' work could be described as feminist empiricism, Unger criticizes this approach, noting that it is removed from social applicability, and one of her key concerns as a feminist is that research be useful in a liberatory sense. Another of her concerns focuses on the generalization inherent to such research: Who is compared to whom? Unger also attends to the limited scope with which feminist psychology's research agenda was carried out, and notes that sexual orientation, ethnicity, class, age, and disability issues were largely off the radar.

Feminist empiricism was seen as somewhat naïve by many in other feminist disciplines, who saw science as an outdated and patriarchal institution, unsuitable for the feminist enterprise.

S. M. van Anders ( $\square)$

Department of Psychological and Brain Sciences, Indiana

University, 1101 East 10th St, Bloomington, IN 47405, USA

e-mail: smvanand@indiana.edu
Unger notes, however, that findings resulting from feminist empiricism can be valuable, especially in supporting legal change, and I would argue that social change in the liberal feminist mold is well-served by feminist empiricism-the two are almost eerily well-matched. Unger makes the case that the practice of feminist empiricism should not be taken as, or concurrent with, a belief in the superiority or infallibility of the scientific method. It should be valued only in its utility as one tool in the box, suitable for some tasks. The tension between feminist empiricism and other feminist epistemologies, though not a main theme in this volume, is a continued subtle undercurrent and I would have liked to see more about how feminist psychology as a whole has grappled with the issue. Unger alludes to this, in noting how little acceptance or welcome feminist psychologists, including her, have had in mainstream academic feminism and its structures. It may be because, as Unger notes, power (in contrast to powerlessness) has never been a "serious" subject in psychology and has emerged only slowly in feminist psychology, even while it is one of the defining topics of study for feminism.

Of course, feminist psychology has been marginalized in mainstream psychology. In Reading 2 (1985), Unger notes that women are more likely to be targets of negative stereotypes when they step outside their normative roles. One might ask (tongue only partially in cheek) whether this explains the lack of acceptance of feminist psychologists in both psychology and feminism. Both areas have normative expectations, and feminist psychologists may not fit into these roles (e.g., psychology: subject matter and relevance; feminism: epistemologies and methods). One major point in the book is that professional legitimacy (respect, tenure, jobs, etc.) is largely a matter of power, and the psychology departments of elite American universities do not generally have feminist psychology classes (or even psychology of gender or women classes, though the landscape has changed somewhat since the volume was published) nor do they have 
an abundance of feminist psychologists in their ranks. On the flip side, it may also be that few of the women's studies departments at these institutions have resident feminist psychologists (especially in the feminist empiricist tradition). Interestingly, Unger alludes to feminist psychology being more generally accepted in Britain, where it may also have more in common with feminist epistemologies than those of psychology. In America, feminist psychology may exist on a bridge between two islands, or, as Unger describes herself as sometimes feeling, a trough between two normal curves.

Though the formal development of feminist psychology began with an interest in topics, critiques of methods did follow. So, while originally feminist psychologists attempted to counteract sex difference research with sex similarity research (finding, for example, that women and men were extraordinarily alike in their belief of sex differences), some began to question the utility of examining sex differences or similarities at all. Unger notes that sex difference research obscures sex similarities and situational determinants, implies a trait view of the variables under study, and, crucially, is used as an explanation instead of a description. Thus, the movement from sex/gender as an internal variable, as in "how do women and men differ" to external, as in "how do the contexts and lives of women and men differ such that different outcomes could be expected" is a key one for Unger.

Indeed, the view of sex/gender as an internal versus external variable is a prime question related not only to methodology and interpretation, but epistemology, and this might be considered one of the major themes of the book. If we believe that reality constructs the person, that we discover truths, and that facts are absolute, then gender/sex is likely to be seen as an unvaried innate cause of behaviors that needs little corrective attention. If we believe that the person constructs reality, that we create truths, and that facts are relative, then gender/sex can be seen as the varied changing result of contextual, historical, and learned behaviors and roles that we are behooved to try and render equitable. Thus, our epistemological approach to gender/sex could be said to embody our epistemological approach, in toto.

Unger is clearly frustrated with mainstream psychologists, who "...remain unwilling to examine their sociopolitical assumptions or to believe that these have anything to do with the way they practice science" (p. 164). She reflects that feminist scholarship has not been acknowledged by the powerbrokers in psychology. However, she also turns her attention to the detractions of feminist postmodern theories, noting that the emphasis on multiple truths highlights individuals and can undermine collective action. As well, the criticisms of feminist psychology have not assisted in constructing "good" feminist science. However, authors like Harding and others in the nascent field of feminist science studies are trying to produce feminist science that is both critical and constructive. Perhaps feminist psychology and its practitioners need to take (or be invited) to play a more integral role in this movement. Still, it is clear that Unger appreciates these various movements: "We are all concerned about the valid means by which truth can be acquired" (p. 127).

A major drawback of this volume is that it makes an unfortunate miscalculation in terms of the familiarity with the subject matter its audience is likely to have. It seems much more suited for those already in the field, despite the explicit avowal that the book is primarily written for those who are new to the psychology of women. Unger does not introduce the major figures (e.g., Weisstein), assuming a base acquaintance that newcomers are extremely unlikely to have. The book would benefit from more contextualization of the players and of the research disciplines of which various feminist psychology findings are a part.

Despite this flaw (and it is not a minor one), Unger leaves the reader not only with insights about the field but poses important and fundamental questions. She asks us to consider what the most useful epistemology is right now, or, which issues need a resolution that can be collectively achieved, as opposed to how younger people can be made to see feminism's relevance. As many others in feminism have come to believe, Unger suggests that feminism must broaden its scope beyond the empowerment of women to social justice coalitions along the intersections, and must move beyond its essentialist tendencies. In addition, she acknowledges the difficulty associated with focusing solely on oppressions (which highlights problems but ignores women as agents of change) or advances (which is empowering but ignores inequities).

Unger notes that "It is easy to become paralyzed out there in the outer margins" (p. 206) but that this marginalization can give the energy to persevere. This rings true. After all, if individual psychologists and scientists can harness their worries of intellectual marginalization (Will I get tenure? Will I have enough publications this year?) to produce the remarkable collective body of science and knowledge with which we now find ourselves, imagine how far even a portion of our feelings of social marginalization could go towards collective social justice, if we were so inclined. 
Copyright of Archives of Sexual Behavior is the property of Springer Science \& Business Media B.V. and its content may not be copied or emailed to multiple sites or posted to a listserv without the copyright holder's express written permission. However, users may print, download, or email articles for individual use. 